\title{
Physiological and Biochemical Responses of Common Bush Bean to Drought
}

\section{Alefsi David SÁNCHEZ-REINOSO, Gustavo Adolfo LIGARRETO-MORENO, Hermann RESTREPO-DÍAZ*}

\author{
Universidad Nacional de Colombia, Facultad de Ciencias Agrarias, Departamento de Agronomía, Carrera 30 No 45-03 Edificio 500, Bogotá, \\ Colombia; adsanchezre@unal.edu.co; galigarretom@unal.edu.co; hrestrepod@unal.edu.co (*correspondingauthor)
}

\begin{abstract}
Agriculture has been adversely affected by the low water availability resulting from climate change, creating environmental stress for the common bean (Phaseolus vulgaris L.). A growth room experiment was performed to evaluate the physiological and biochemical responses of the several bush bean genotypes to water deficit conditions. Plants in soil with $20 \mathrm{~g} \cdot \mathrm{L}^{-1}$ polyethylene glycol 6000 (PEG) were subjected to drought for $15 \mathrm{~d}$. The levels of photosynthesis, stomatal conductance and transpiration in all genotypes decreased by approximately $65 \%$ under water deficit conditions compared with the corresponding values in the controls. Water use efficiency was enhanced by water deficit conditions, with 'Bianca' plants exhibiting the highest values $\left(28.08 \mu \mathrm{mol} \cdot \mathrm{mol}^{-1}\right)$, followed by 'NUA35', 'Bachue' and 'Cerinza' (20.46, 20.11 and 18.21 $\mu \mathrm{mol} \cdot \mathrm{mol}^{-1}$, respectively). The 'Bianca' plants exhibited a lower relative tolerance index (50\%), and water deficit increased the levels of leaf photosynthetic pigments, chlorophyll and carotenoids in this genotype by approximately $100 \%$. The photosynthetic efficiency, which was evaluated using the $F_{v} / F_{m}$ ratio and rapid light-derived parameters (the maximum electron transport rate and a light saturation parameter), decreased due to water deficit conditions, particularly in the 'Bianca' plants, in which these parameters were reduced by approximately $60 \%$. The proline and malondialdehyde (MDA) contents were increased by the addition of PEG, primarily in the 'Bacatá' and 'Bianca' plants. In conclusion, our results suggest that rapid light-response curves can be useful for characterizing genotypes because they represent an easy and non-destructive tool for understanding acclimatization mechanisms under water deficit conditions. In addition, all genotypes exhibited susceptibility to water deficit conditions, and the most susceptible genotype was 'Bianca', as reflected by a significant reduction in the electron transport rate and the presence of oxidative damage (high MDA content and electrolyte leakage), suggesting that this cultivar could not adapt well to landscaping situations in which periods of extreme water deficit can be expected.
\end{abstract}

Keywords: lipid peroxidation; photosynthesis; proline; rapid light-response curves; relative tolerance index

\section{Introduction}

The common bean (Phaseolus vulgaris $\mathrm{L}$.) is a traditional crop of the neotropics and a primary source of protein in the diets of populations in developing countries (Beebe $e t$ al., 2012). A significant production constraint of common bean crops is water deficit, which affects up to $60 \%$ of beanproducing regions (Beebe et al., 2012). In the Andean region, $P$. vulgaris is mainly grown by small holder farmers, often under unfavorable conditions due to drought and heat (Beebe et al., 2008; Omae et al., 2012).

Climate change adversely affects food production due to increased drought in production areas (Dai, 2011). Global warming can generate changes in rainfall patterns in the Andean countries, affecting the availability of water for agriculture (Bradley et al., 2006). By 2050, climate change will affect $80 \%$ of crops in Colombia, causing changes in crop phenology and ultimately the product chain of common beans (Ramirez-Villegas et al., 2012).

Plants display adverse effects in growth, development and yield in response to water deficit (Lobell and Gourdji, 2012). Knowledge of plant physiology has helped identify strategies used by drought-resistant genotypes to cope with water deficits (Polania et al., 2016). P. vulgaris plants under water deficit conditions adopt higher water use efficiency (WUE) (De Laat, 2014; Polania et al., 2016). Polania et al. (2016) also stated that a characteristic of bean genotypes 
394

with drought tolerance is the ability to mobilize photosynthates to pods and seeds. Others have reported that a greater root length under water deficit conditions contributes to improved drought resistance of the common bean (White and Castillo, 1992; Polania et al., 2009).

The chlorophyll fluorescence technique has become important in plant ecophysiological studies because photosystem II (PSII) is sensitive to water deficit ( $\mathrm{Lu}$ and Zhang, 1999; Maxwell and Johnson, 2000). Consequently, chlorophyll fluorescence parameters are used to screen for tolerance to abiotic stress (Sayed, 2003). Rapid lightresponse curves allow measurement of the effective quantum yield as a function of irradiance. This technique provides complete information on the saturation characteristics of electrons and is a powerful tool for assessing photosynthetic activity (Ralph et al., 2002). The rapid light curve-derived parameters [the maximum relative electron transport rate (ETRmax), minimum saturating irradiance (Ek) and initial slope of the curve $(\alpha)$ ] indicate photosynthetic efficiency in plants under stress (Xu et al., 2013).

Plants exposed to water deficit exhibit other acclimation mechanisms, such as (i) decreased leaf chlorophyll content (Chavez et al., 2002), (ii) increased proline production (Rosales et al., 2012), and (iii) cell membrane damage due to lipid peroxidation, causing the generation of peroxide ions and malondialdehyde (MDA) (Sánchez-Rodríguez et al., 2010). Biochemical parameters are important markers for categorizing susceptible and/or tolerant genotypes with respect to responses to water deficit (Ghanbari et al., 2013; Siddiqui et al., 2015).

A physiological approach can help increase the available knowledge regarding the behavior of common bean genotypes to climate change (Restrepo-Diaz et al., 2010; Polania et al., 2016). The aim of this study was to evaluate phenotypic differences in the water deficit tolerances of common bush bean genotypes growing in regions where periods of drought can be expected based on physiological and biochemical traits.

\section{Materials and Methods}

\section{Biological materials and growth conditions}

The experiment was performed from September to November 2014 in a growth room of the Faculty of Agricultural Sciences at Universidad Nacional de Colombia, Bogotá Campus ( $4^{\circ} 35^{\prime} 56^{\prime \prime} \mathrm{N}$ and 740.4'51" W). Seeds of the following bush bean genotypes were used: 'Cerinza' and 'Bachue', which have been used in traditional Colombian agriculture for 20 years, 'NUA35', which is a genotype developed by CIAT that has been commercialized for nine years since its release, and 'Bianca' and 'Bacatá', which are cultivars that have been released for less than two years.

Seeds were pre-germinated in a growth chamber for 7 days in the dark at a relative humidity $(\mathrm{RH})$ of $75 \%$ and an ambient temperature of $25^{\circ} \mathrm{C}$ and then transplanted into a floating hydroponic system in $80-\mathrm{L}$ glass containers. The following environmental conditions were maintained in the growth room throughout the experiment: a day/night temperature of $26 / 22{ }^{\circ} \mathrm{C}, \mathrm{RH}$ of 60 to $80 \%$, and a $12-\mathrm{h}$ artificial photoperiod using incandescent lamps supplying $800-\mu \mathrm{mol} \cdot \mathrm{m}^{-2} \cdot \mathrm{s}^{-1}$ photosynthetically active radiation (PAR). The plants were grown in a nutrient solution using a liquid $40 \mathrm{~N}-4 \mathrm{P}-20 \mathrm{~K}$ fertilizer containing micronutrients (NutriPonic, Walco S.A., Bogotá D.C., Colombia) at a rate of 2.5 $\mathrm{mL} \cdot \mathrm{L}^{-1}$; the $\mathrm{pH}$ ranged from 5.5 to 6.0. The nutrient solution was refilled every other day to maintain a constant volume $(42 \mathrm{~L})$ in the containers and was always aerated by an electric bomb.

\section{Deficit treatments}

Water deficit was imposed when plants had three or four fully expanded trifoliate leaves, approximately 40 days after transplanting (DAT). The water deficit treatment was induced by the addition of polyethylene glycol 6000 (PEG) (PanReac, Barcelona, Spain) to the nutrient solution at a rate of $20 \mathrm{~g} \cdot \mathrm{L}^{-1}$ (De Laat et al., 2014). The plants were exposed to the solution containing PEG from 40 to 55 DAT.

\section{Physiological measures}

The relative water content (RWC) in fully expanded leaves from the upper part of the canopy was determined. The leaves were collected at 55 DAT for all genotypes. The RWC was calculated according to the equation described by Clavijo-Sánchez et al. (2015) using fresh and turgid weights after submergence in distilled water for $24 \mathrm{~h}$ at $4{ }^{\circ} \mathrm{C}$ in the dark.

The levels of photosynthesis $(\mathrm{Pn})$, stomatal conductance (g) and transpiration (E) in a fully expanded trifoliate leaf from the upper half of the plants were measured at 54 and 55 DAT between 10:00 and 15:00 using a portable photosynthesis meter (LSPro-SD, ADC BioScientific Ltd., UK). The chamber conditions during leaf gas exchange measurements were the following: PAR, $800 \mu \mathrm{mol} \cdot \mathrm{m}^{-2} \cdot \mathrm{s}^{-1}$; leaf temperature, $25 \pm 2{ }^{\circ} \mathrm{C}$; and $\mathrm{CO}_{2}$ concentration, $400 \pm$ $10 \mu \mathrm{mol} \cdot \mathrm{mol}^{-1}$. The extrinsic water use efficiency (WUE) was calculated as the $\mathrm{Pn} / \mathrm{E}$ ratio.

The plants were harvested at $55 \mathrm{DAT}$ and dried in a compressed air oven at $70{ }^{\circ} \mathrm{C}$ for $48 \mathrm{~h}$ to obtain the leaf, stem, root and total plant dry weights. The shoot:root ratio $(S / R)$ was calculated based on the relationship between the dry weight of the aerial parts (leaves and stem) to that of the roots. Additionally, the relative tolerance index (RTI) was obtained using the equation described by Dutta Gupta et al. (1995).

The $\mathrm{F}_{\mathrm{v}} / \mathrm{F}_{\mathrm{m}}$ ratio and rapid light-response curves (RLCs) at 54 and 55 DAT were determined using a modulated chlorophyll fluorescence meter (MINI-PAM, Walz, Effeltrich, Germany). After measurement of the leaf-gas exchange, the same leaves were adapted to the dark for 15 min. The $F_{v} / F_{m}$ measurements were performed by applying a pulse with a maximum light intensity of up to 2.600 $\mu \mathrm{mol} \cdot \mathrm{m}^{-2} \cdot \mathrm{s}^{-1}$ to the surface of leaf samples. The RLCs were constructed by plotting the electron transport rate (ETR) versus the increasing actinic irradiance (from 1 to 1.795 $\left.\mu \mathrm{mol} \cdot \mathrm{m}^{-2} \cdot \mathrm{s}^{-1}\right)$ with 10 -s intervals between the irradiance levels. The parameters $\alpha$ (initial slope), ETR max $_{\max }$ (maximum ETR) and $I_{k}$ (a light-saturation parameter) were estimated using the model described by Xu et al. (2014). 
The leaf photosynthetic pigments were measured at 55 DAT, and approximately $30 \mathrm{mg}$ of the second fully expanded trifoliate leaf was homogenized in $4 \mathrm{~mL}$ of $80 \%$ acetone. Subsequently, the samples were centrifuged (Model 420101, Becton Dickinson Primary Care Diagnostics, MD, USA) at $3000 \mathrm{~g}$ to remove particles. The supernatant was diluted to a final volume of $6 \mathrm{~mL}$ by adding acetone. The leaf chlorophyll content was measured at 663 and $646 \mathrm{~nm}$, and the carotenoid levels were determined at $470 \mathrm{~nm}$ using a spectrophotometer (Spectronic BioMate 3 UV-VIS, Thermo, WI, USA). The equations described by Wellburn (1994) were used to calculate the leaf photosynthetic pigment contents.

\section{Electrolyte leakage, lipid peroxidation and proline content}

Damage to the plasma membrane was estimated as the percentage of electrolyte leakage at 55 DAT following the method described by Sanchez-Reinoso et al. (2014). Five discs $(0.5 \mathrm{~cm}$ diameter $)$ from the second fully expanded trifoliate leaf were extracted in 50-mL Falcon tubes using 25 $\mathrm{mL}$ of deionized water as the medium. The initial electrical conductivity of the samples $\left(C E_{I}\right)$ was recorded with a conductivity meter (Model P700, Oakton Instruments, Vernon Hills, IL, USA). The samples were placed in a water bath (Model B-480, Büchi Labortechnik AG, Switzerland) at $30^{\circ} \mathrm{C}$ for $2 \mathrm{~h}$, and the final electrical conductivity $\left(C E_{2}\right)$ was then measured after $20 \mathrm{~min}$ in a water bath at $90^{\circ} \mathrm{C}$.

The thiobarbituric acid (TBA) method described by Hodges et al. (1999) was used to assess lipid oxidation based on the MDA concentration. Approximately $0.3 \mathrm{~g}$ of homogenized plant material was collected at 55 DAT and stored in liquid nitrogen. The samples were centrifuged at $3000 \mathrm{~g}$, and the absorbance values at 440, 532 and $600 \mathrm{~nm}$ were estimated using a spectrophotometer (Spectronic BioMate 3 UV-VIS, Thermo, WI, USA). An extinction coefficient was used $\left(157 \mathrm{M} \cdot \mathrm{mL}^{-1}\right)$ to calculate the MDA concentration.

Approximately $0.3 \mathrm{~g}$ of homogenized plant material was collected from the second fully expanded trifoliate leaf at 55 DAT and stored in liquid nitrogen. The absorbance was measured at $520 \mathrm{~nm}$ using a spectrophotometer (Spectronic), and the proline concentration was determined using a standard curve and the equation described by Bates et al. (1973).

\section{Experimental design and statistical analysis}

A factorial design, in which the first factor was the water stress treatment and the second factor was the cultivars evaluated, resulting in a total of 10 treatments with four replicates (40 seedlings in total), was adopted. Percentage values were transformed using the arcsine function. A variance analysis followed by the comparative Tukey's test was performed. The data were analyzed using Statistix (ver. 9.0, Analytical Software, Tallahassee, FL, USA), and SigmaPlot (version 10.0; Systat Software, San Jose, CA, USA) was used to draw three-dimensional plots and to perform cluster analysis.

\section{Results and Discussion}

\section{Physiologicalmeasures}

Most of the variables were affected by the water treatment or genotype and their interaction (Table 1); however, the relative water content was affected by the water treatment but not the genotype or their interaction, and stomatal conductance was not affected by genotype. The plants under water deficit conditions had a lower RWC compared with the control plants (Fig. 1). RWC is an important physiological measurement that helps quantify a plant's water status under normal or drought

Table 1. Effects of water stress on the physiological behavior of Phaseolus vulgaris $\mathrm{L}$. genotypes based on ANOVA

\begin{tabular}{|c|c|c|c|c|}
\hline \multirow{2}{*}{ Variable } & \multirow{2}{*}{ Abbreviation } & \multicolumn{3}{|c|}{ Variance source } \\
\hline & & Water treatment $(\mathrm{W})$ & Genotype $(\mathrm{G})$ & Interaction $(W \times G)$ \\
\hline Relative water content & RWC & $* * *$ & NS & NS \\
\hline Photosynthesis & $\operatorname{Pn}$ & *** & ** & * \\
\hline Stomatal conductance & $g_{s}$ & *** & NS & *** \\
\hline Transpiration & E & *** & $* * *$ & * \\
\hline Water use efficiency & WUE & *** & $* * *$ & *** \\
\hline Aerial dry weight & $\mathrm{ADW}$ & $* *$ & *** & $*$ \\
\hline Root dry weight & RDW & *** & *** & * \\
\hline Total dry weight & TDW & *** & *** & ** \\
\hline Shoot:root ratio & $\mathrm{AP} / \mathrm{R}$ & NS & $* * *$ & $* * *$ \\
\hline Chlorophyll a & Chl a & ${ }^{* *}$ & *** & *** \\
\hline Chlorophyll $b$ & Chl b & * & $* * *$ & *** \\
\hline Total chlorophyll content & Chl total & $*$ & *** & *** \\
\hline Carotenoids & $\mathrm{Cx}+\mathrm{c}$ & * & $* * *$ & *** \\
\hline Maximum efficiency of PSII & $\mathrm{F}_{\mathrm{v}} / \mathrm{F}_{\mathrm{m}}$ & *** & $*$ & * \\
\hline Electrolyte leakage & & *** & $*$ & ** \\
\hline Malondialdehyde & MDA & *** & $* *$ & $*$ \\
\hline Proline & & *** & *** & *** \\
\hline Initial slope & $\alpha$ & *** & *** & ** \\
\hline Maximum relative electron transport rate & $\mathrm{ETR}_{\max }$ & *** & * & *** \\
\hline Light saturation parameter & $\mathrm{E}_{K}$ & *** & *** & *** \\
\hline
\end{tabular}




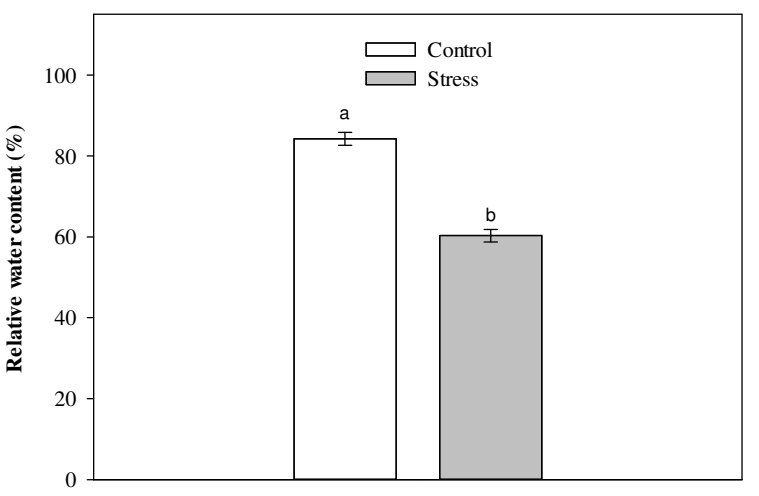

Fig. 1. Effect of water deficit on the relative water content (RWC) in leaves of common bean (Phaseolus vulgaris L.). The bars represent the means of 20 data points \pm standard errors
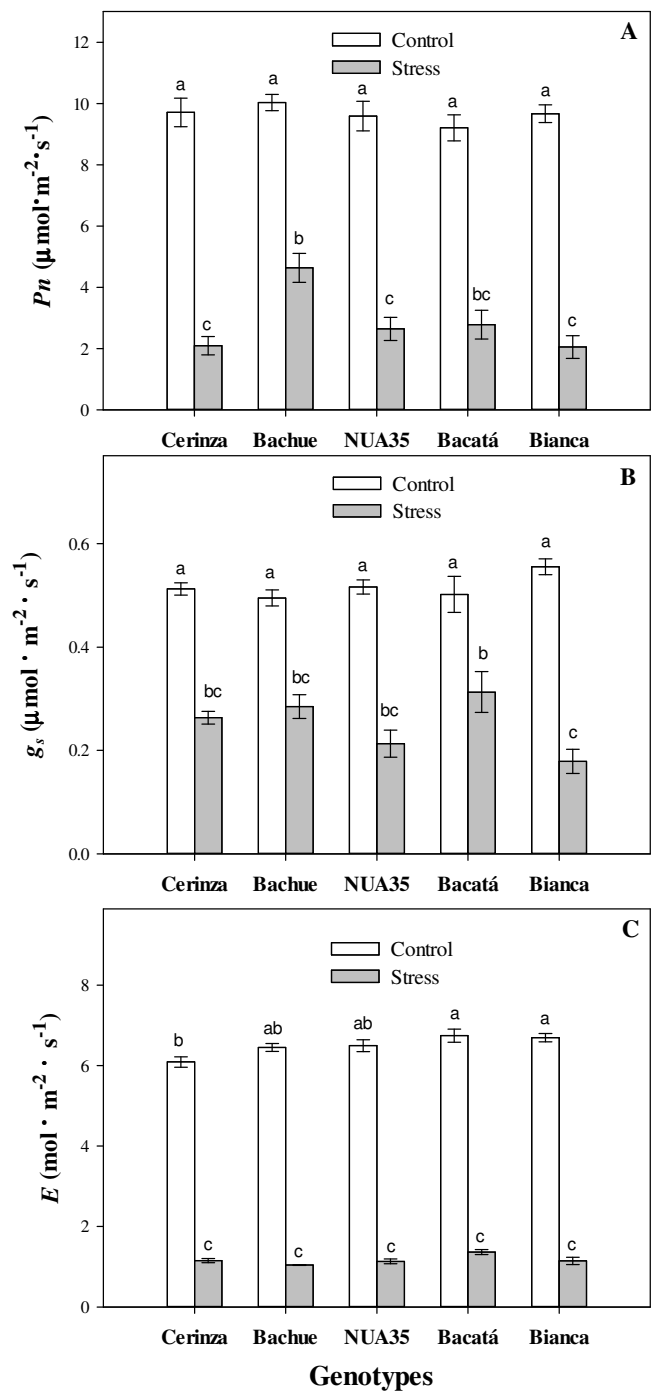

Fig. 2. Effects of the interaction between genotype and water treatment on net photosynthesis (Pn) (A), stomatal conductance $\left(\mathrm{g}_{\mathrm{s}}\right)(\mathrm{B})$ and leaf transpiration $(\mathrm{E})(\mathrm{C})$ in the bush bean genotypes. The data represent the average of four plants per treatment $(n=4)$. The means followed by the same letter are not significantly different according to Tukey's test at $P \leq$ 0.05 conditions (Keyvan, 2010). Reduced RWC values indicate that plant-water relationships might be affected by adverse abiotic conditions, which could reduce the photosynthetic rate (Costa-França et al., 2000).

The interaction between water treatment and genotype affected Pn (Table 1). In response to water deficit, the Pn level in 'Bachue' decreased by approximately 60\%, whereas that in 'Bacatá', 'Bianca', 'Cerinza' and 'NUA35' decreased by approximately $80 \%$ (Fig. 2A). The water deficit condition caused the greatest $\mathrm{g}_{s}$ reduction in 'Bianca' (Fig. 2B). Additionally, E decreased by approximately $70 \%$ across all genotypes in response to the imposed water deficit (Fig. 2C). Lanna et al. (2016) and Mathobo et al. (2017) found that a moderate water deficit led to a severe reduction $(\geq 45 \%)$ in photosynthesis. Water deficit can inhibit leaf photosynthesis due to alterations in the photosynthetic apparatus, a reduced stomatal aperture, decreased transpiration, changes in light absorption, and alterations of the biochemical pathways associated with $\mathrm{CO}_{2}$ fixation (Farooq, 2009).

WUE was significantly affected by the interaction between water treatment and genotype (Table 1). In general, differences were not observed between genotypes under control conditions. However, when the plants were subjected to water deficit, the WUE of all the genotypes increased. 'Bianca' had the highest values, followed by the 'NUA35', 'Bachue' and 'Cerinza' cultivars (Fig. 3). Increased WUE in $P$. vulgaris genotypes has been reported to occur as a physiological response to water-stress
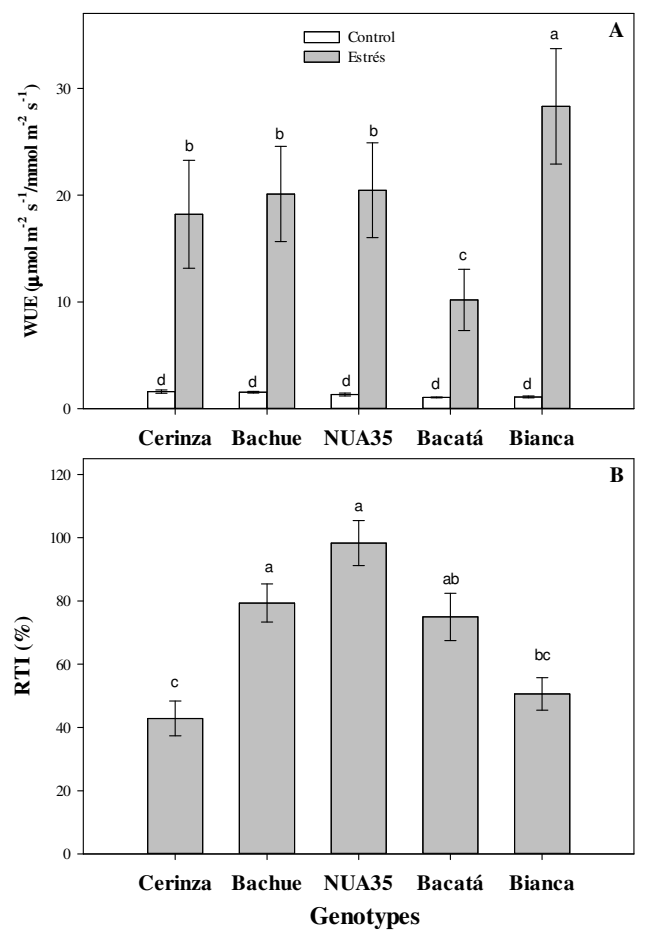

Fig. 3. Effects of the interaction between genotype and water deficit on water use efficiency (WUE) (A) and the relative tolerance index (RTI) (B) in the common bean genotypes (Phaseolus vulgaris L). The data represent the average of four plants per treatment $(n=4)$. The means followed by the same letter are not significantly different according to Tukey's test at $P \leq 0.05$ 
conditions (Munoz-Perea et al., 2007; Lanna et al., 2016), suggesting that greater WUE under water deficit conditions can likely lead to reductions in seed production and resistance to water stress (Polania et al., 2016).

The interaction also affected the plants' aerial parts and roots, the total plant dry weights and the shoot:root ratio (Table 2). In general, the 'Cerinza' plants under the water deficit conditions had the lowest aerial part dry matter compared with the other genotypes. The root dry weights of 'Bianca', 'Bacatá', 'Cerinza' and 'NUA35' were reduced by the water deficit, whereas the root dry weight of 'Bachue' plants increased. The total plant dry weights of 'Bianca', 'Bacatá' and 'Cerinza' accumulated less biomass under the water deficit conditions, but the biomass of 'Bachue' and 'NUA35' did not vary between treatments. The 'Cerinza', 'Bianca', and 'Bachue' plants had lower shoot:root ratios compared with the 'Bacatá' and 'NUA35' plants. It has been reported that a water deficit results in less biomass accumulation in $P$. vulgaris genotypes (Munoz-Perea et al., 2007; Lanna et al., 2016, Mathobo et al., 2017). However, Polania et al. (2016) reported that a higher root dry weight under drought conditions is an important physiological trait that could be used to characterize a tolerant genotype. 'Bachue' produces a vigorous root system, suggesting that this genotype might be tolerant to drought.

Stress indices, such as the RTI, have been used to screen genotypes in response to water deficits. Tolerant genotypes exhibit the highest RTI scores (Fernandez, 1993). The RTI results revealed different drought-tolerant responses among the genotypes and in response to the water treatment. The 'Cerinza' and 'Bianca' plants had the lowest values, indicating that these genotypes are susceptible to drought (Fig. 4). Susceptible genotypes have been reported to exhibit lower biomass accumulation, as reflected by a lower RTI (Darkwa et al., 2016).

In general, the chlorophyll $\mathrm{a}$ and $\mathrm{b}$ and the total chlorophyll contents of the plants subjected to water deficit did not vary compared with the corresponding values in the control plants, except for 'Bianca'. In 'Bianca', the leaf chlorophyll contents ( $\mathrm{a}, \mathrm{b}$ and total) were 2-fold higher than those in the control plants (Fig. 5 A, B, C). 'Bianca' plants exposed to water deficit exhibited a higher leaf carotenoid content than the control plants (Fig. 5D).

The ability to maintain the leaf chlorophyll content under abiotic stress has been used as a parameter in the selection of tolerant cultivars (Kiani-Pouya and Rasouli, 2014). The leaf carotenoid content (another leaf photosynthetic pigment) also plays a role in tolerance to drought (Farooq et al., 2009). The levels of leaf photosynthetic pigments were favorable under moderate water deficit, particularly in 'Bianca'. An increase in the contents of these pigments can be considered a response mechanism to reduce the adverse effects of water deficitinduced photoinhibition (Silva et al., 2007).

'Bianca' plants had a lower $\mathrm{F}_{\mathrm{v}} / \mathrm{F}_{\mathrm{m}}$ ratio than the 'Cerinza', 'Bachue', 'NUA35' and 'Bacatá' under water deficit conditions (Fig. 6). The RLCs showed differences between water treatments (Fig. 7). The ETR values of all genotypes under water deficit conditions generally decreased due to an increase in actinic irradiance. Higher $\alpha$ values were obtained for all genotypes under water deficit conditions, whereas ETR ${ }_{\max }$ and $\mathrm{I}_{K}$ decreased. Similar results have been found for bush clover (Lespedeza davurica (Lax.) Schindl) (Xu et al., 2014). RLCs represent a tool for estimating photosynthetic activity because these measurements provide complete information on the saturation characteristics of electrons (Ralph et al., 2002), and decreases in $\mathrm{ETR}_{\max }$ and $\mathrm{I}_{K}$ indicate a reduction in the photosynthetic efficiency of plants under abiotic stress (Song et al., 2013). 'Bianca' plants consistently exhibited lower rapid light-derived parameters $\left(\mathrm{ETR}_{\max }\right.$ and $\left.\mathrm{I}_{K}\right)$ and $\mathrm{F}_{\mathrm{v}} / \mathrm{F}_{\mathrm{m}}$ ratios compared with the other genotypes, indicating that the photosynthetic activity was severely affected by the water deficit.

Table 2. Effects of the interaction between water deficit and genotype on the initial slope of the curve $(\alpha)$, the maximum electron transport rate $\left(\mathrm{ETR}_{\max }\right)$ and minimum saturation irradiance $\left(\mathrm{I}_{K}\right)$

\begin{tabular}{cccc}
\hline Treatment & $\begin{array}{c}\alpha \\
\left(\mu \mathrm{mol} \cdot \mathrm{m}^{-2} \cdot \mathrm{s}^{-1}\right)\end{array}$ & ETRmax & $\begin{array}{c}\mathrm{I}_{K} \\
\left(\mu \mathrm{mol} \cdot \mathrm{m}^{-2} \cdot \mathrm{s}^{-1}\right)\end{array}$ \\
\hline Cerinza $\times$ Control & $0.45 \mathrm{c}^{\mathrm{a}}$ & $74.80 \mathrm{abc}$ & $210.07 \mathrm{c}$ \\
\hline Bachue $\times$ Control & $0.36 \mathrm{c}$ & $88.07 \mathrm{ab}$ & $249.85 \mathrm{~b}$ \\
NUA35 $\times$ Control & $0.72 \mathrm{~b}$ & $64.88 \mathrm{bc}$ & $131.58 \mathrm{~d}$ \\
\hline Bacatá $\times$ Control & $0.31 \mathrm{c}$ & $73.54 \mathrm{abc}$ & $303.15 \mathrm{a}$ \\
\hline Bianca $\times$ Control & $0.32 \mathrm{c}$ & $91.90 \mathrm{a}$ & $302.44 \mathrm{a}$ \\
\hline Cerinza $\times$ Stress & $1.19 \mathrm{a}$ & $30.03 \mathrm{e}$ & $24.23 \mathrm{e}$ \\
Bachue $\times$ Stress & $1.02 \mathrm{a}$ & $29.30 \mathrm{e}$ & $32.73 \mathrm{e}$ \\
\hline NUA35 $\times$ Stress & $1.10 \mathrm{a}$ & $33.84 \mathrm{de}$ & $32.51 \mathrm{e}$ \\
\hline Bacatá $\times$ Stress & $0.73 \mathrm{~b}$ & $57.66 \mathrm{~cd}$ & $97.82 \mathrm{~d}$ \\
\hline Bianca $\times$ Stress & $1.04 \mathrm{a}$ & $18.42 \mathrm{e}$ & $16.90 \mathrm{e}$ \\
\hline Significance & & $\cdots$ \\
\hline
\end{tabular}

${ }^{* *}$ and ${ }^{* * *}$ refer to interaction data analyzed using the least squares means and means separated at $\mathrm{P}<0.05$ and $\mathrm{P}<0.01$, respectively.

${ }^{a}$ The data represent the average of four plants per treatment $(\mathrm{n}=4)$. The means followed by the same letter are not significantly different according to Tukey's test at $P$ $\leq 0.05$. 

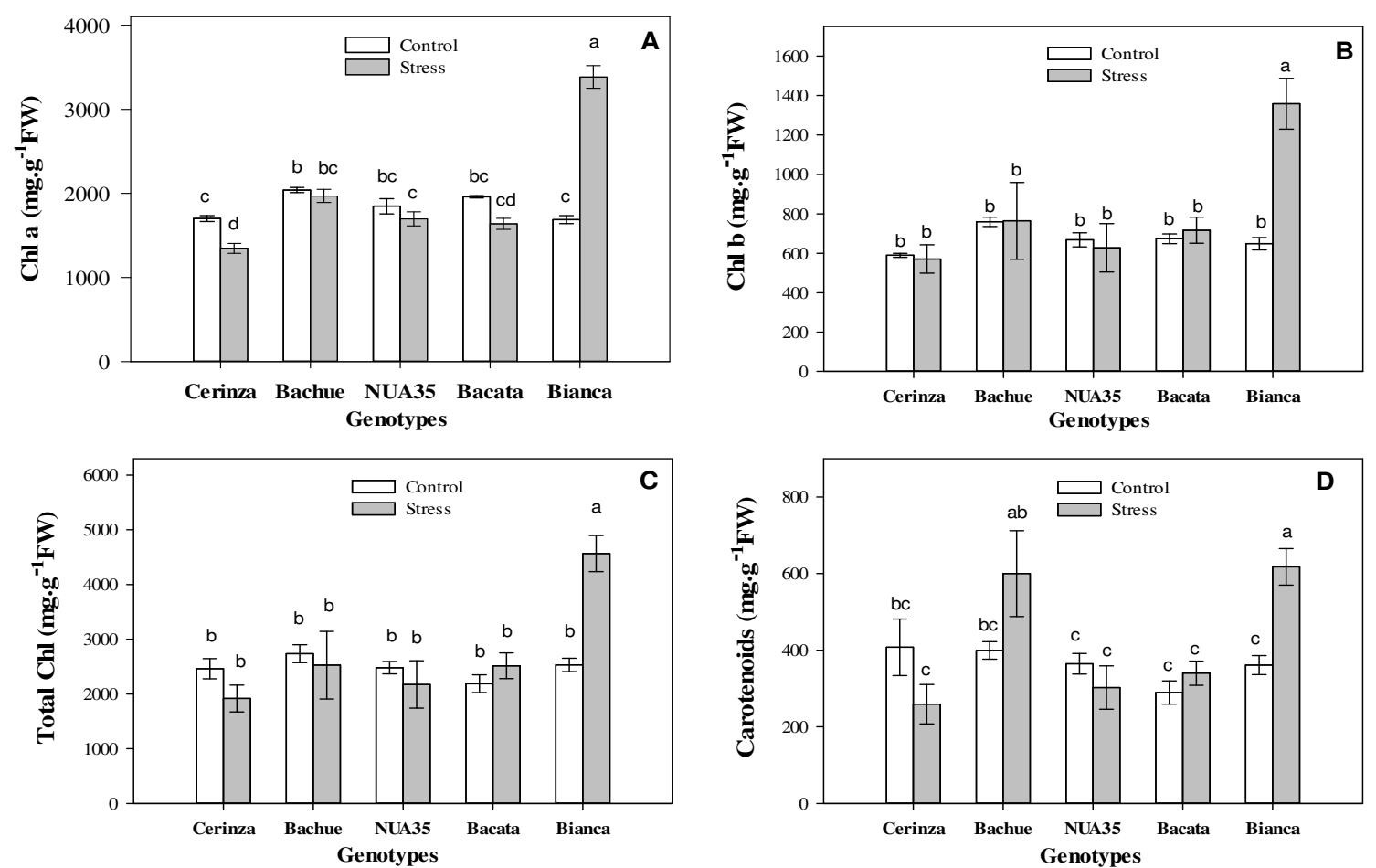

Fig. 4. Effects of the interaction between genotype and water deficit on the total chlorophyll (A), chlorophyll $a$ (B), chlorophyll $b$ (C) and total carotenoid (D) contents in the leaves of common bush bean (Phaseolus vulgaris L.). The data represent the average of four plants per treatment $(\mathrm{n}=4)$. The means followed by the same letter are not significantly different according to Tukey's test at $\mathrm{P} \leq 0.05$

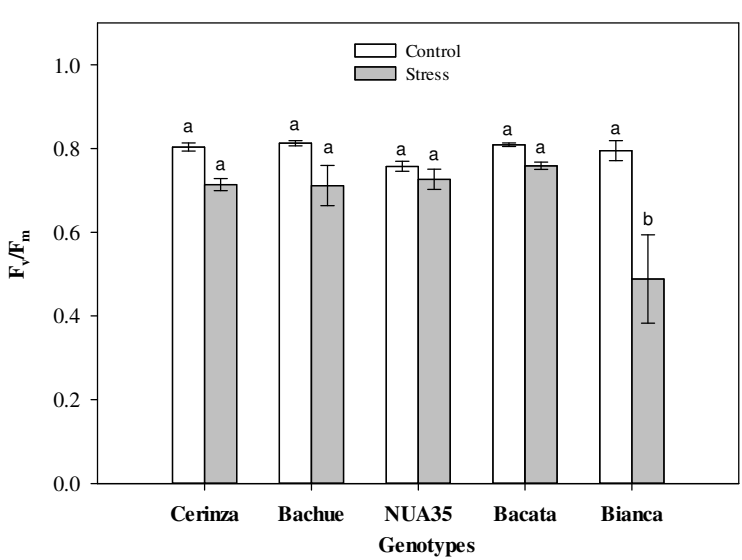

Fig. 5. Effect of the interaction between genotype and water deficit on the PSII efficiency $\left(\mathrm{F}_{\mathrm{v}} / \mathrm{F}_{\mathrm{m}}\right)$ in leaves of common bush bean (Phaseolus vulgaris $\mathrm{L}$ ). The data represent the average of four plants per treatment $(n=4)$. The means followed by the same letter are not significantly different according to Tukey's test at $P \leq 0.05$

\section{Electrolyte leakage, lipid peroxidation and proline content}

Electrolyte leakage and the MDA and proline contents were affected by the interaction between water treatment and genotype. Electrolyte leakage in the 'Cerinza', 'NUA35', 'Bacatá' and 'Bianca' genotypes increased under water deficit conditions, and 'Bachue' plants maintained levels similar to those measured in the controls (Fig. 7A). A higher MDA content was observed in all the genotypes subjected to water deficit conditions, and the highest values were obtained in the 'Bianca' and 'Bacatá' plants (Fig. 7B). Additionally, the leaf proline content increased under water deficit conditions: 'Cerinza' and 'Bianca' had the highest values of this osmolyte, followed by 'Bacatá', 'NUA35' and 'Bachue' (Fig. 7C). Water deficits have been reported to enhance the proline and MDA contents of common bean and faba bean (Vicia faba L.) (Ghanbari et al., 2013; Siddiqui et al., 2015).

Increases in the proline content under water deficit conditions help maintain hydration in cells and prevent damage. This amino acid acts as an osmolyte and as a storage source for carbon and nitrogen, which are subsequently used to stabilize macromolecules, proteins and cell membranes in plant tissues (George et al., 2015). Proline has been proposed as a biochemical marker to determine the tolerance of a genotype to water deficit conditions (Naser $e t$ al., 2010). Higher MDA accumulation indicates greater damage at the cellular level due to increased membrane lipid peroxidation (Sanchez-Reinoso et al., 2014). It has been reported that a higher proline content, a lower MDA production and electrolyte leakage under water deficit conditions are useful indicators of plant tolerance, and these features can be used for the selection of tolerant genotypes (Liu et al., 2013; Sanchez-Reinoso et al., 2014). The results obtained from the analyses of the leaf proline content, electrolyte leakage and MDA content plots indicate that 'Bacatá' and 'Cerinza' are drought-susceptible genotypes based on (Fig. 8). The cluster analysis identified 'Bianca' as a drought-susceptible genotype, 'Cerinza', 'Bacatá' and 'NUA35' as moderately susceptible genotypes, and 'Bachue' as moderately tolerant to water deficit conditions (Fig. 9). 

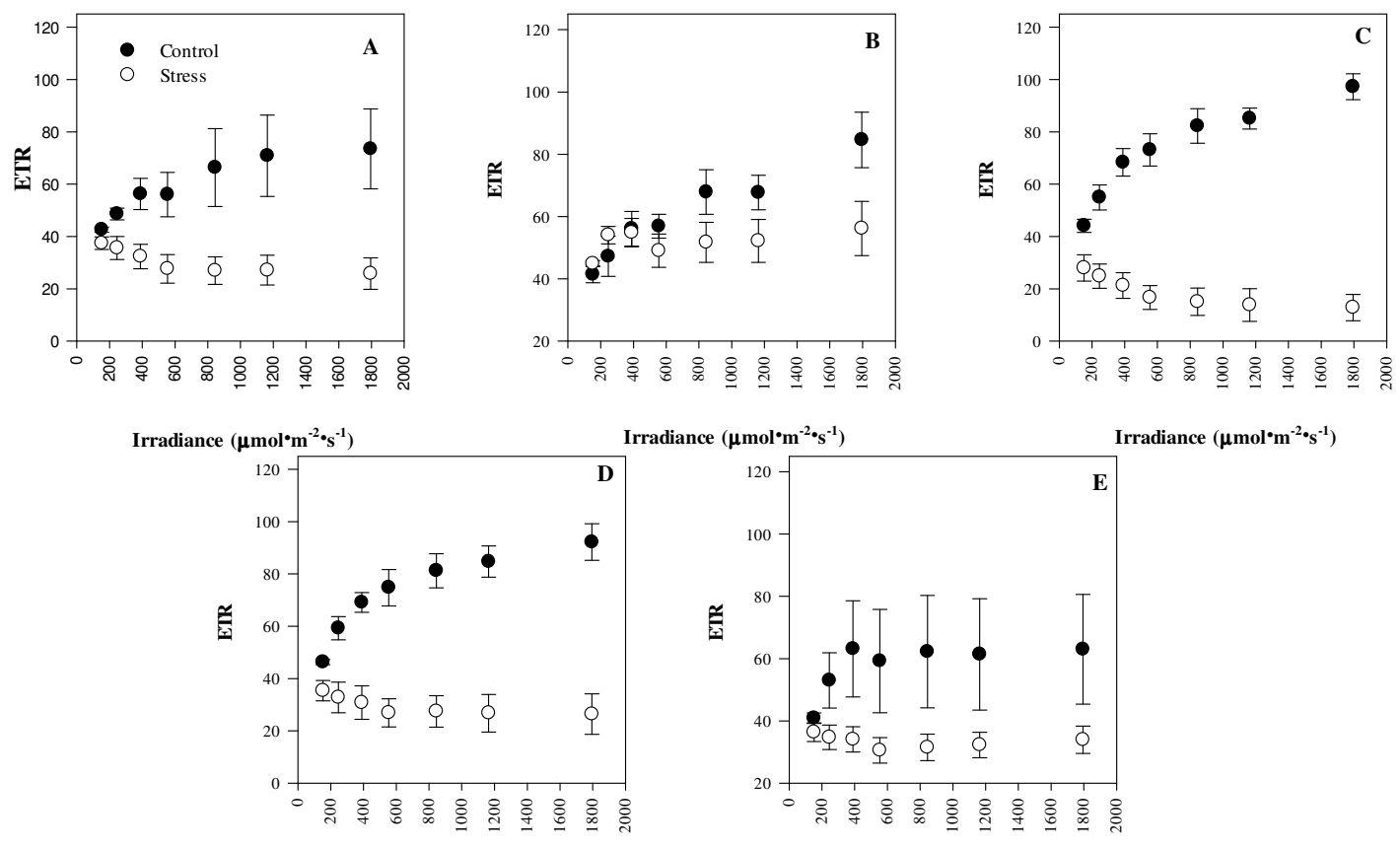

Irradiance $\left(\mu \mathrm{mol}^{\cdot} \cdot \mathrm{m}^{-2} \cdot \mathrm{s}^{-1}\right)$

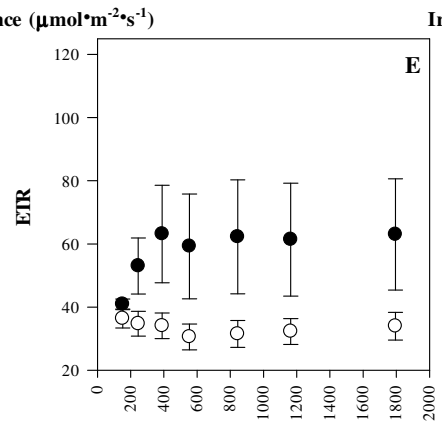

Irradiance $\left(\mu \mathrm{mol} \cdot \mathrm{m}^{-2} \cdot \mathrm{s}^{-1}\right)$

Fig. 6. Rapid light-response curves of 'Cerinza' (A), 'Bacatá' (B), 'Bianca' (C), 'Bachue' and 'NUA35' (D) genotypes due to water deficit. The data represent the mean of four data points \pm standard errors

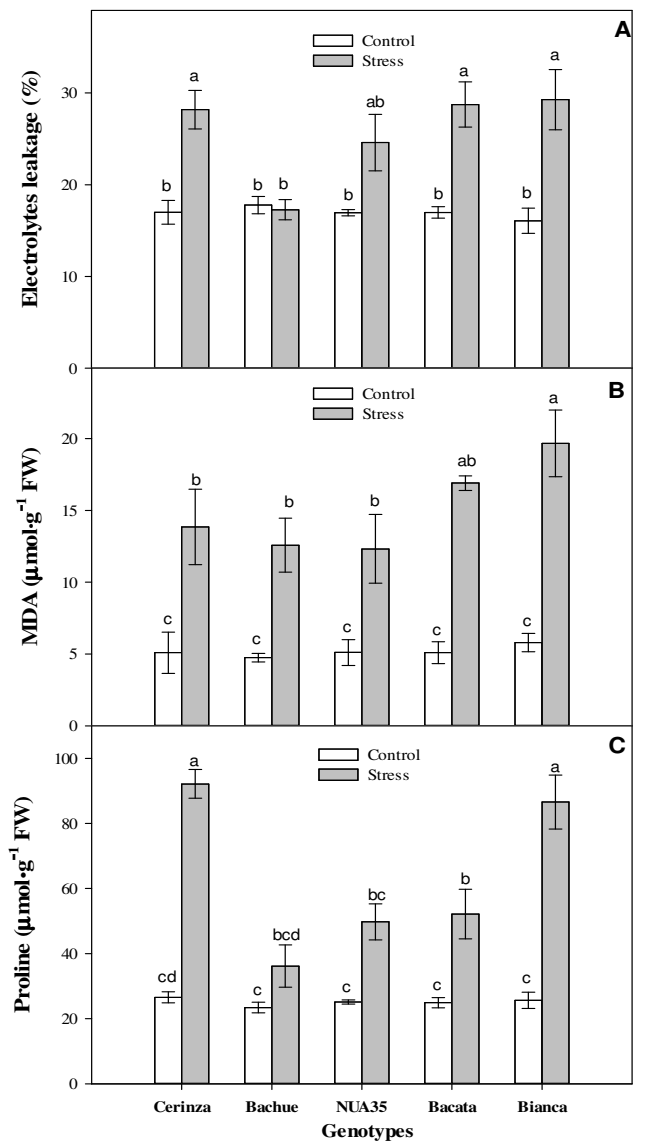

Fig. 7. Effects of the interaction between genotype and water deficit on electrolyte leakage (A), MDA content (B) and proline content $(\mathrm{C})$ measured in the leaves of common bush bean (Phaseolus vulgaris L.) genotypes. The data represent the average of four plants per treatment $(\mathrm{n}=4)$. The means followed by the same letter are not significantly different according to Tukey's test at $P \leq 0.05$

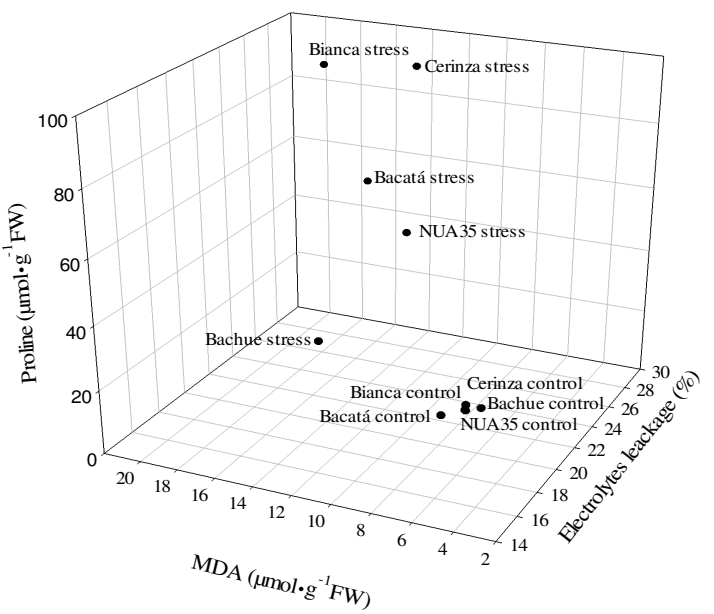

Fig. 8. Three-dimensional plot (proline content, MDA content and electrolyte leakage) for common bush bean (Phaseolus vulgaris $\mathrm{L}$.) genotypes under water deficit conditions. The data represent the mean of four data points

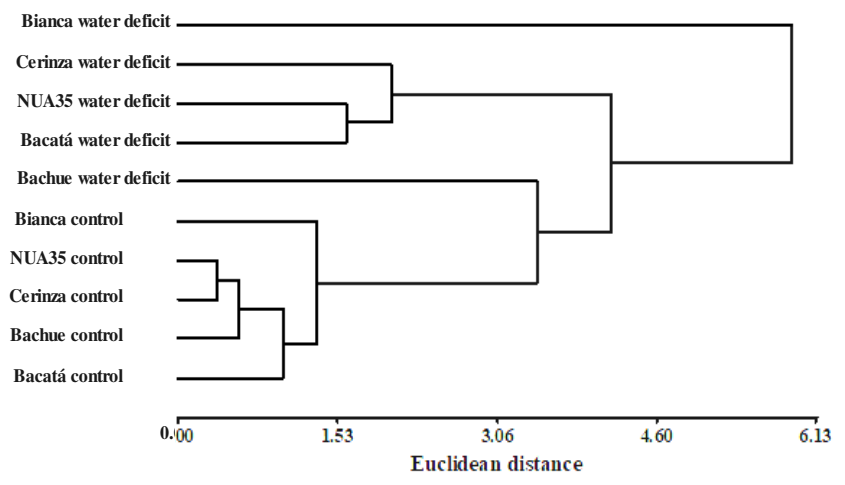

Fig. 9. Dendrogram using the Euclidean distance to characterize common bush bean (Phaseolus vulgaris L.) genotypes under control and water deficit conditions 
400

\section{Conclusions}

'Bianca' was identified as the most susceptible genotype to water deficit, and 'Bachue' can be considered moderately tolerant to short periods of water deficit and can adapt to arid regions or to situations in which periods of moderate drought can be expected. Our results indicate that physiological variables such as $\mathrm{Pn}$, the $\mathrm{F}_{\mathrm{v}} / \mathrm{F}_{\mathrm{m}}$ ratio, RLCs and the MDA and proline contents can be used to characterize genotypes that are tolerant to water deficit conditions.

\section{References}

Bates L, Waldren R, Teare I (1973). Rapid determination of free proline for water-stress studies. Plant and Soil 39:205-207.

Beebe S, Rao IM, Cajiao C, Grajales M (2008). Selection for drought resistance in common bean also improves yield in phosphorus limited and favorable environments. Crop Science 48:582-592.

Beebe S, Rao IM, Mukankusi C, Buruchara R (2012). Improving resource use efficiency and reducing risk of common bean production in Africa, Latin America and the Caribbean. In: Hershey C (Ed). Issues in tropical agriculture. I. Eco-efficiency: From vision to reality. International Center for Tropical Agriculture (CIAT), Cali, Colombia pp 117-134.

Beebe SE, Rao IM, Blair MW, Acosta-Gallegos JA (2013). Phenotyping common beans for adaptation to drought. Frontiers in Physiology 4:120.

Bradley RS, Vuille M, Diaz HF, Vergara W (2006). Threats to water supplies in the tropical Andes. Science 312:1755-1756.

Chaves MM, Pereira JS, Maroco J, Rodrigues ML, Ricardo CPP, Osorio ML, Carvalho I, Faria T, Pinheiro C (2002). How plants cope with water stress in the field? Photosynthesis and growth. Annals of Botany 89:907-916.

Clavijo-Sánchez N, Flórez-Velasco N, Restrepo-Díaz H (2015). Potassium Nutritional Status Affects Physiological Response of Tamarillo Plants (Cyphomandra betacea Cav.) to Drought Stress. Journal of Agricultural Science and Technology 17:1839-1849.

Costa-Franca MG, Pham-Thi AT, Pimentel C, Pereyra-Rossiello RO, Zuily-Fodil Y, Laffray D (2000). Differences in growth and water relations among Phaseolus vulgaris cultivars in response to induced drought stress. Environmental and Experimental Botany 43:227-237.

Dai A (2011). Drought under global warming: A review. WIREs Climate Change 2:45-65.

Darkwa K, Ambachewa D, Mohammed H, Asfawa A, Blair MW (2016). Evaluation of common bean (Phaseolus vulgaris L.) genotypes for drought stress adaptation in Ethiopia. The Crop Journal 4:367-376.

De Laat D, Colombo C, Chiorato A, Carbonell S (2014). Induction of ferritin synthesis by water deficit and iron excess in common bean (PhaseolusvulgarisL.). Molecular Biology Reports 41:1427-1435.

Dutta Gupta S, Auge RM, Denchev PD, Conger BV (1995). Growth, proline accumulation and water relations in NaCl-selected and nonselected callus lines of Dactylis glomerata. Environmental and Experimental Botany 35:83-92

Farooq M, Wahid A, Kobayashi N, Fujita D, Basra SMA (2009). Plant drought stress: Effects, mechanisms and management. Agronomy for SustainableDevelopment 29:185-212
Fernandez CGJ (1993). Effective selection criteria for assessing plant stress tolerance. In: Kuo CG (Ed). Adaptation of food crops to temperature and water stress: Proceedings of an international symposium. Asian Vegetable Research and Development Centre, Shanhua, Taiwan pp 257-270.

George S, Minhas NM, Jatoi SA, SiddiquiSU, Ghafoor A (2015). Impact of polyethylene gycol on proline and membrane stability index for water stress regime in tomato (Solanum lycopersicum). Pakistan Journal of Botany 47:835-844.

Ghanbari AA, Mousavi SH, Mousapour-Gorji A, Rao I (2013). Effects of water stress on leaves and Seeds of bean (Phaseolus vulgaris L.). Turkish Journal of Field Crops 18:73-77.

Hodges DM, DeLong JM, Forney CF, Prange RK (1999). Improving the thiobarbituric acid-reactive-substances assay for estimating lipid peroxidation in plant tissues containing anthocyanin and other interfering compounds. Planta 207:604-611.

Keyvan S (2010). The effects of drought stress on yield, relative water content, proline, soluble carbohydrates and chlorophyll of bread wheat cultivars. Journal of Animal and Plant Science 8:1051-1060.

Kiani-Pouya A, Rasouli F (2014). The potential of leaf chlorophyll content to screen bread-wheat genotypes in saline condition. Photosyntetica 52:288-300.

Lanna AC, Mitsuzono ST, Terra TGR, Vianello RP, Carvalho MAF (2016). Physiological characterization of common bean (Phaseolus vulgaris $\mathrm{L}$.) genotypes, water-stress induced with contrasting response towards drought. Australian Journal of CropScience 10:1-6.

Liu, H., Sultan MARF, Zhao HX (2013). The screening of water stress tolerant wheat cultivars with physiological indices. Global Journal Of Biodiversity Science And Management 3:211-218.

Lobell DB, Gourdji SM (2012). The influence of climate change on global crop productivity. Plant Physiology 160:1686-1697.

Lu C, Zhang J (1999). Effects of water stress on photosystem II photochemistry and its thermostability in wheat plants. Journal of Experimental Botany 50:1199-1206.

Maxwell, K, Jhonson GN (2000). Chlorophyll fluorescence-a practical guide. Journal of Experimental Botany 51:659-668.

Mathobo R, Maraisa D, Steyn JM (2017). The effect of drought stress on yield, leaf gaseous exchange andchlorophyll fluorescence of dry beans (Phaseolusvulgaris L.). Agricultural Water Management 180:118-125.

Munoz-Perea CG, Allen RG, Westermann DT, Wright JL, Singh SP (2007). Water use efficiency among dry bean landraces and cultivars in drought-stressed and non-stressed environments. Euphytica 155:393402.

Naser L, Kourosh V, Bahman K, Reza A (2010). Soluble sugars and proline accumulation play a role as effective indices for drought tolerance screening in Persian walnut (Juglans regia L.) during germination. Fruits 65:97-112.

Omae H, Kumar A,Shono M (2012). Adaptation to high temperature and water deficit in the common bean (Phaseolus vulgaris L.) during the reproductive period. Journal of Botany 2012:1-6.

Polanía JA, Rao IM, Beebe S, García R (2009). Root development and distribution under drought stress in common bean (Phaseolus vulgaris L.) in a soil tube system. Agronomía Colombiana 27:25-32. 
401

Polania J, Rao IM, Cajiao C, Rivera M, Raatz B, Beebe S (2016). Physiological traits associated with drought resistance in Andean and Mesoamerican genotypes of common bean (Phaseolus vulgaris L.). Euphytica210:17-29.

Ralph PJ, Polk SM, Moore KA, Orth RJ, Smith, Jr. WO (2002). Operation of the xanthophyll cycle in the seagrass (Zostera marina) in response to variable irradiance. Journal of Experimental Marine Biology and Ecology 271:189-207.

Ramírez-Villegas J, Salazar M, Jarvis A, Navarro-Racines CE (2012). A way forward on adaptation to climate change in Colombian agriculture: perspectives towards 2050. Climatic Change 115:611-628.

Restrepo-Díaz H, Melgar JC, Lombardini L (2010). Ecophysiology of horticultural crops: An overview. Agronomía Colombiana 28:71-79.

Rosales MA, Ocampo E, Rodríguez-Valentín R, Olvera-Carrillo Y, AcostaGallegos J, Covarrubias AA (2012). Physiological analysis of common bean (Phaseolus vulgaris L.) cultivars uncovers characteristics related to terminal drought resistance. Plant Physiology and Biochemistry 56:24 34.

Sánchez-Reinoso AD, Garcés-Varón G, Restrepo-Díaz H (2014). Biochemical and physiological characterization of three rice cultivars under different daytime temperature conditions. Chilean Journal of Agricultural Research 74:373-379.

Sánchez-Rodríguez E, Rubio-Wilhelmi M, Cervilla LM, Blasco JJ, Rios JJ, Rosales MA, Romero L, RuizJM (2010). Genotypic differences in some physiological parameters symptomatic for oxidative stress under moderate drought in tomato plants. Plant Science 178:30-40.
Sayed OH (2003). Chlorophyll fluorescence as a tool in cereal crop research. Photosynthetica 41:321-330.

Siddiqui MH, Al-Khaishany MY, Al-Qutami MA, Al-Whaibi MH, Grover A, Ali HM, Al-Wahibi MS, Bukhari NA (2015). response of different genotypes of Faba bean plant to drought stress. International Journal of Molecular Sciences 16:10214-10227.

Silva MA, Jifon JL, Da Silva JAG, Sharma V (2007). Use of physiological parameters as fast tools to screen for drought tolerance in sugarcane. Brazilian Journal of Plant Physiology 19:193-201.

Song R, Zhao CY, Liu J, ZhangJ, Du YX, Li JZ, Sun HZ, Zhao HB, Zhao QZ (2013). Effect of sulphate nutrition on arsenic translocation and photosynthesis of rice seedlings. Acta Physiologia Plantarum 35:32373243.

Wellburn AR (1994). The spectral determination of chlorophylls a and b, as well as total carotenoids, using various solvents with spectrophotometers of different resolution. Journal of Plant Physiology 144:307-313.

White JW, Castillo JA (1992). Evaluation of diverse shoot genotypes on selected root genotypes of common bean under soil water deficits. Crop Science 32:762-765.

Xu WZ, Deng XP, Xu BC, Gao ZJ, Ding WL (2014). Photosynthetic activity and efficiency of Bothriochloa ischaemum and Lespedeza davurica in mixtures across growth periods under water stress. Acta Physiologia Plantarum 36:1033-1044. 